\title{
Inhibitory Effects of $\alpha$-Arbutin on Melanin Synthesis in Cultured Human Melanoma Cells and a Three-Dimensional Human Skin Model
}

\author{
Kazuhisa Sugimoto, ${ }^{*}, a$ Takahisa Nishimura, ${ }^{a}$ Koji Nomura, ${ }^{a}$ Kenji Sugimoto, $^{b}$ and Takashi Kuriki ${ }^{a}$ \\ ${ }^{a}$ Biochemical Research Laboratory, Ezaki Glico Co., Ltd.; 4-6-5 Utajima, Nishiyodogawa-ku, Osaka 555-8502, Japan: \\ and ${ }^{b}$ Laboratory of Applied Molecular Biology, Division of Applied Biochemistry, Graduate School of Agriculture and \\ Biological Sciences, Osaka Prefecture University; 1-1 Gakuen-cho, Sakai, Osaka 599-8531, Japan.
}

Received September 12, 2003; accepted December 24, 2003

We studied the inhibitory effects of 4-hydroxyphenyl $\alpha$-glucopyranoside ( $\alpha$-arbutin) on melanogenesis in cultured human melanoma cells, HMV-II, and in a three-dimensional cultured human skin model. $\alpha$-Arbutin showed no inhibitory effect on HMV-II cell growth at a concentration below $1.0 \mathrm{~mm}$. Melanin synthesis in cells treated with $\alpha$-arbutin at $0.5 \mathrm{~mm}$ decreased to $76 \%$ of that in non-treated cells. The cellular tyrosinase activity of HMV-II cells also significantly decreased, while the expression of its mRNA was not affected. Melanin synthesis in a human skin model was also evaluated by the macro- and microscopic observation of its pigmentation as well as by quantitative measurements of melanin. Treatment of the human skin model with $250 \mu \mathrm{g}$ of $\alpha$-arbutin did not inhibit cell viability, while melanin synthesis was reduced to $40 \%$ of that in the control. These results indicate that $\alpha$-arbutin is an effective and safe ingredient for skin-lightening.

Key words $\quad \alpha$-arbutin; melanin; inhibition; human tyrosinase; human melanoma cell; three-dimensional human skin model

Hyperpigmentation in the epidermis is caused by excessive melanin synthesis, and tyrosinase (EC 1.14.18.1) is a key-enzyme in melanin synthesis. It catalyzes the first two steps in melanin synthesis: the hydroxylation of tyrosine to 3-(3,4-dihydroxyphenyl)-alanine (DOPA) and the oxidation of DOPA to dopaquinone. Several tyrosinase inhibitors have been used as skin-lightening agents in the cosmetic industry.

4-Hydroxyphenyl $\alpha$-D-glucopyranoside ( $\alpha$-arbutin; Fig. 1$)$ was enzymatically synthesized from hydroquinone and saccharides, ${ }^{1-4)}$ and its inhibitory activity against tyrosinases from mushroom, B16 mouse melanoma and HMV-II human melanoma cells has been examined previously, ${ }^{2,5,6)} \alpha$-Arbutin specifically inhibited mammalian tyrosinases, and its effect on human tyrosinase was the strongest among the hydroquinone-glycosides that we have studied so far. $\left.{ }^{6}\right)$

In this study, we examined the inhibitory effects of $\alpha$-arbutin on melanin biosynthesis in cultured human melanoma cells and in a three-dimensional human skin model.

\section{MATERIALS AND METHODS}

Cell Culture Human malignant melanoma cells, HMV$\mathrm{II}^{7)}$ were provided by the Cell Resource Center for Biomedical Research, Tohoku University. The cells were cultured in F12/DMEM (GIBCO) supplemented with $10 \%$ fetal bovine serum at $37{ }^{\circ} \mathrm{C}$ in a humidified atmosphere of $5 \% \mathrm{CO}_{2}$ in air.

The three-dimensional cultured human skin model, MelanoDerm, (MEL312B; a co-culture of normal human melanocytes (NHM) from black donors and normal human keratinocytes (NHK)) was purchased from Kurabo Co. (Osaka, Japan). The human skin model was maintained ac-

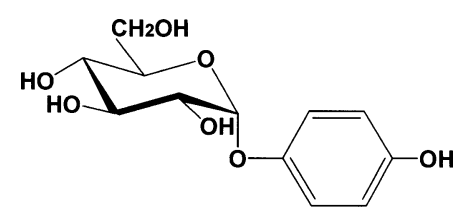

Fig. 1. Structure of $\alpha$-Arbutin cording to the manufacturer's instructions.

Reagents L-DOPA and synthetic melanin were purchased from Sigma Chemical Co. (St. Louis, MO, U.S.A.). Medium for the human skin model [long life maintenance medium (LLMM)] was supplied with the MEL-312B kit. Other chemicals were purchased from Wako Pure Chemical Industries, Ltd. (Osaka).

Preparation of $\alpha$-Arbutin $\alpha$-Arbutin was prepared by the method described by Nishimura et al. ${ }^{1)} \alpha$-Amylase from Bacillus sp. strain X-23 was added to $100 \mathrm{ml}$ of $50 \mathrm{~mm}$ sodium acetate buffer solution ( $\mathrm{pH} 5.0$ ) containing $5 \%$ hydroquinone and $20 \%$ maltopentaose. After incubation at $40^{\circ} \mathrm{C}$ for $16 \mathrm{~h}$, glucoamylase from Aspergillus niger was added, and the mixture was incubated at $40{ }^{\circ} \mathrm{C}$ for $4 \mathrm{~h}$. $\alpha$-Arbutin was purified from the reaction mixture by extraction with ethyl acetate and charcoal column chromatography.

Assay of Melanin Synthesis by HMV-II Cells HMV-II cells $\left(1.0 \times 10^{6}\right)$ were plated with $10 \mathrm{ml}$ of medium in a 100 $\mathrm{mm}$ dish and grown for $10 \mathrm{~d}$. On days 1, 4 and 7, the medium was changed to fresh medium containing various concentrations of $\alpha$-arbutin.

Determination of Melanin Content The melanin content of cells was measured by the method of Hosoi et al. ${ }^{8)}$ with a minor modification. HMV-II cells grown in a $100-\mathrm{mm}$ dish were washed with $\mathrm{Mg}^{2+}-, \mathrm{Ca}^{2+}$-free phosphate-buffered saline [PBS(-)]. After being treated with $0.25 \%$ trypsin, the cells were harvested by centrifugation at $1000 \times \boldsymbol{g}$ for $10 \mathrm{~min}$ and sonicated in $0.5 \mathrm{ml}$ of $1 \%$ Triton X-100/PBS(-) on ice. In contrast, the human skin model was harvested and sonicated in $0.5 \mathrm{ml}$ of $\operatorname{PBS}(-)$. The lysate was centrifuged at $10000 \times \boldsymbol{g}$ for $10 \mathrm{~min}$ and the pellet was incubated with $0.04 \%$ Proteinase $\mathrm{K} / \mathrm{PBS}(-)$ at $45^{\circ} \mathrm{C}$ for $18 \mathrm{~h}$. After centrifugation at $10000 \times \boldsymbol{g}$ for $10 \mathrm{~min}$, the pellet was sonicated in $0.5 \mathrm{ml}$ of $1 \%$ Triton X-100/PBS(-) on ice. For a quantitative measurement of melanin, acid-insoluble materials were obtained by extracting the pellet twice with $10 \%$ trichloroacetic acid. The precipitate was washed once with $100 \%$ ethanol, dried and then solubilized by incubating with $1 \mathrm{ml}$ of $1 \mathrm{~N} \mathrm{NaOH}-10 \%$ dimethyl sulfoxide at $80^{\circ} \mathrm{C}$ for $2 \mathrm{~h}$. Syn- 
thetic melanin was also solubilized and used as a standard solution. The absorbance of the solutions was measured at $470 \mathrm{~nm}$ and the melanin content was calculated as $\mu \mathrm{g} / 10^{6}$ cells.

$\alpha$-Arbutin Treatment and Cell Proliferation Determination HMV-II cells $\left(1.0 \times 10^{6}\right)$ were grown for $6 \mathrm{~d}$ in $10 \mathrm{ml}$ of medium containing various concentrations of $\alpha$-arbutin, with the medium changed on day 3 . The cells were treated with $0.25 \%$ trypsin and the cell number was counted with a hemocytometer.

Assay of Cellular Tyrosinase Activity Cellular tyrosinase activity was assayed based on the method of Tomita et $a l .{ }^{9)}$ using L-DOPA as a substrate. A total of $2.0 \times 10^{4} \mathrm{HMV}$ II cells in $100 \mu \mathrm{l}$ of medium, containing various concentrations of $\alpha$-arbutin, were added to a 96-well plate and incubated for $6 \mathrm{~d}$. On days 1 and 4, the medium was changed to fresh medium. The $\alpha$-arbutin-treated cells were washed with $\operatorname{PBS}(-)$ and lysed with $0.5 \%$ Triton-X/PBS $(-) \quad(100$ $\mu \mathrm{l} /$ well). The lysates were mixed by vibration, and $50 \mu \mathrm{l}$ of $10 \mathrm{~mm}$ L-DOPA was added to each well. After incubation at $37^{\circ} \mathrm{C}$ for $3 \mathrm{~h}$, the absorbance at $475 \mathrm{~nm}$ was measured by a spectrophotometer.

Reverse Transcription-Polymerase Chain Reaction (RT-RCR) Total RNA was prepared using a QuickPrep Total RNA Extraction kit (Amersham Pharmacia Biotech) from HMV-II cells grown in the presence or absence of $0.5 \mathrm{~mm} \alpha$-arbutin for $6 \mathrm{~d}$. Two hundred nanograms of the total RNA were reverse-transcribed and the synthesized cDNA was amplified using Ready-to-GO RT-PCR beads (Amersham Pharmacia Biotech) in a total volume of $50 \mu \mathrm{l}$ containing $0.5 \mu \mathrm{g} \mathrm{pd}(\mathrm{T})_{12-18}$-first strand primer, $400 \mathrm{~nm}$ sense primer and $400 \mathrm{~nm}$ antisense primer. Programmable Thermal Cycler conditions were $42^{\circ} \mathrm{C}$ for $30 \mathrm{~min}, 95^{\circ} \mathrm{C}$ for $5 \mathrm{~min}, 18,20,22$ or 24 cycles at $95^{\circ} \mathrm{C}$ for $0.5 \mathrm{~min}, 60^{\circ} \mathrm{C}$ for $0.5 \mathrm{~min}$ and $72^{\circ} \mathrm{C}$ for $2 \mathrm{~min}$, and a final treatment at $72^{\circ} \mathrm{C}$ for $7 \mathrm{~min}$. The following oligonucleotides were used; human tyrosinase gene primers (GenBank accession Nos. E06554 and A24706): sense, 5'-TCCAATGCACCACTTGGGCCT-3'; antisense, 5'-GCTATCCCAGTAAGTGGACT-3'; human glyceraldehyde-3-phosphate dehydrogenase (G3PDH) gene primers $^{10)}$ : sense, $5^{\prime}$-ACCACAGTCCATGCCATCAC-3'; antisense, 5'-TCCACCACCCTGTTGCTGTA-3'.

Culture of the Human Skin Model The human skin model was placed in 6-well plates and incubated for $1 \mathrm{~h}$ at $37^{\circ} \mathrm{C}$ in $5 \% \mathrm{CO}_{2}$. The $\alpha$-arbutin solution $(0-500 \mu \mathrm{g}$ dissolved in $0.1 \mathrm{ml}$ of ultrapure water) was applied to the surface of the tissue. The tissue was incubated for $13 \mathrm{~d}$, and fed with $5 \mathrm{ml}$ of fresh LLMM on days $0,2,4,6,8$ and 10 . On days 12 and 13, the tissue surface was rinsed twice with PBS $(-)$ and $100 \mu$ l of ultrapure water was applied to the surface to remove $\alpha$-arbutin in the tissue which may react with MTT. After cultivation for $15 \mathrm{~d}$, the viability of the tissue cells was measured by MTT assay.

MTT Assay The human skin model was placed in a 24well plate, $0.3 \mathrm{ml}$ of MTT solution (MTT diluted with medium: $1 \mathrm{mg} / \mathrm{ml}$ ) was added to each well and the tissue was incubated at $37^{\circ} \mathrm{C}$ in $5 \% \mathrm{CO}_{2}$ for $3 \mathrm{~h}$. After incubation, the tissues were washed twice with $\operatorname{PBS}(-)$. Two milliliters of MTT extraction solution (isopropanol containing $0.04 \mathrm{M}$ $\mathrm{HCl}$ ) and $40 \mu \mathrm{l}$ of sodium dodecyl sulfate (to aid extraction) were then added to each well, and the plate was shaken gen- tly at room temperature for $2 \mathrm{~h}$. The absorbance of extracts was measured at $570 \mathrm{~nm}-660 \mathrm{~nm}$.

Statistical Analysis Results are expressed as mean士 S.E.M. One-way analysis of variance (ANOVA) with Fisher's PLSD post hoc test was used to assess the statistical significance of differences, with a $p$ value of $<0.05$ used as a measure of significance.

\section{RESULTS}

Effect of $\alpha$-Arbutin on Melanin Synthesis To investigate the effects of $\alpha$-arbutin on melanogenesis, HMV-II human melanoma cells were cultured in F12/DMEM containing various concentrations of $\alpha$-arbutin for $10 \mathrm{~d}$. An acidinsoluble fraction was prepared from the cells and the amount of melanin was quantitatively measured by the

A

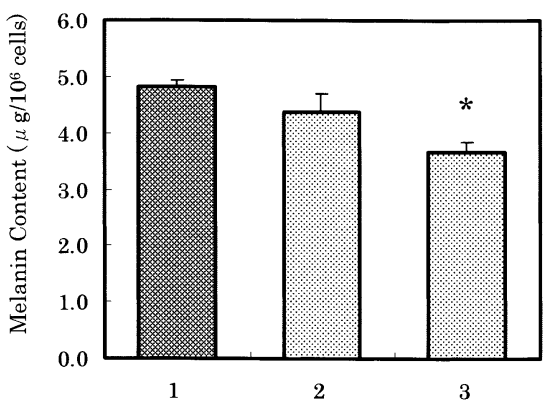

B
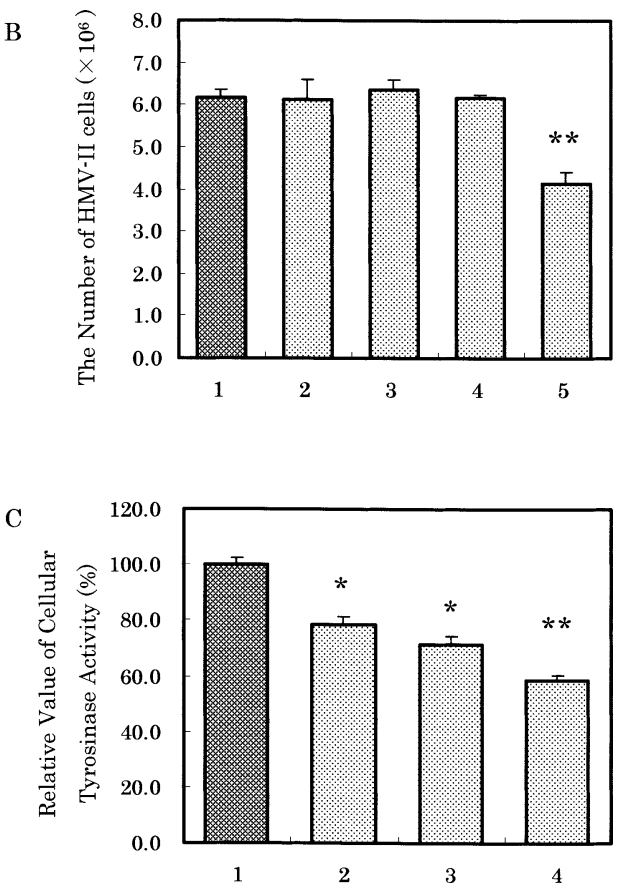

Fig. 2. Effects of $\alpha$-Arbutin on Melanin Synthesis, Cell Growth and Cellular Tyrosinase Activity of HMV-II Cells

HMV-II cells were cultured in the presence or absence of $\alpha$-arbutin as described in Materials and Methods. A: Results of the quantification of melanin synthesis. 1: control, 2: $0.25 \mathrm{~mm} \alpha$-arbutin, 3: $0.5 \mathrm{~mm} \alpha$-arbutin. B: Results of a cell proliferation assay. 1: control, 2: $0.25 \mathrm{~mm} \alpha$-arbutin, 3: $0.5 \mathrm{~mm} \alpha$-arbutin, 4: $1.0 \mathrm{~mm} \alpha$-arbutin, 5: $2.0 \mathrm{~mm}$ $\alpha$-arbutin. C: Results of the measurement of cellular tyrosinase activity. 1: control, 2: $0.13 \mathrm{~mm} \alpha$-arbutin, 3: $0.25 \mathrm{~mm} \alpha$-arbutin, 4: $0.5 \mathrm{~mm} \alpha$-arbutin. Bars represent means \pm S.E. of at least three independent experiments. $*$ Significantly different from the nontreated control group at $p<0.05$. $* *$ Significantly different from the non-treated control group and other $\alpha$-arbutin-treated groups at $p<0.05$. 
method of Hosoi et ll. $^{8)}$ The cellular content of melanin was reduced by the addition of $\alpha$-arbutin to the medium in a dose-dependent manner (Fig. 2A). Melanin synthesis was significantly inhibited at $0.5 \mathrm{~mm}$, at which the melanin content was reduced to $76 \%$ of that in non-treated cells.

Effects of $\boldsymbol{\alpha}$-Arbutin on Cell Viability To exclude the possibility that the above inhibitory effects of $\alpha$-arbutin on melanogenesis might be caused by the inhibition of cell growth, we compared the number of cells grown in the presence and absence of $\alpha$-arbutin. As shown in Fig. 2B, $\alpha$-arbutin did not seem to inhibit cell viability at a concentration below $1.0 \mathrm{~mm}$. However, the number of cells was apparently reduced at $2.0 \mathrm{~mm}$. These results indicate that $\alpha$-arbutin had an inhibitory effect on melanogenesis at noncytotoxic concentrations ( $\leqq 1 \mathrm{~mm})$.

Effects of $\alpha$-Arbutin on Cellular Tyrosinase Activity We then examined the inhibitory action of $\alpha$-arbutin on cellular tyrosinase activity in HMV-II cells. As shown in Fig. $2 \mathrm{C}$, treatment of the cells with $\alpha$-arbutin reduced cellular tyrosinase activity in a dose-dependent manner. The tyrosinase activity was reduced to $60 \%$ of that in the control at $0.5 \mathrm{~mm}$, at which cell viability was not affected (see Fig. 2B, column 3).

Effects of $\alpha$-Arbutin on the Expression of the Tyrosinase Gene To determine whether the expression of the tyrosinase gene was affected by $\alpha$-arbutin, we measured mRNA levels by a semi-quantitative reverse transcriptionpolymerase chain reaction (RT-PCR) assay. The total cellular RNA was extracted from cells treated with $0.5 \mathrm{~mm} \alpha$-arbutin for $6 \mathrm{~d}$. After reverse transcription, DNA fragments were am- plified by PCR using two sets of primers specific for the human tyrosinase gene and the human glyceraldehyde-3phosphate dehydrogenase (G3PDH) gene. No significant difference was observed in tyrosinase gene expression between the $\alpha$-arbutin-treated and non-treated HMV-II cells (data not shown).

Effects of $\alpha$-Arbutin on Melanin Synthesis in a Cultured Human Skin Model To examine the effects of $\alpha$-arbutin on natural skin pigmentation, we used a three-dimensional cultured human skin model. Figure $3 \mathrm{~A}$ shows the macroscopic darkening of the human skin model grown in the presence of different amounts of $\alpha$-arbutin. Darkening of the model was clearly inhibited by the addition of $125 \mu \mathrm{g}$ of $\alpha$-arbutin. When the cultured tissue was observed under an inverted microscope, there appeared to be fewer darkened melanocytes in $\alpha$-arbutin-treated tissue than in non-treated tissue (Fig. 3B).

To quantitatively evaluate the inhibitory effect of $\alpha$-arbutin on cellular melanin synthesis, an acid-insoluble fraction was prepared from the tissues and the amount of melanin was measured (Fig. 4). When $\alpha$-arbutin was applied at 125 and $250 \mu \mathrm{g} /$ tissue for $13 \mathrm{~d}$, the melanin production was reduced to $70 \%$ and $40 \%$ of that in non-treated cells, respectively. In this assay, most of the $\alpha$-arbutin permeated the tissues, since $70 \%$ of the total $\alpha$-arbutin that was applied to the surface of tissue was recovered in the medium after incubation for $48 \mathrm{~h}$. Nevertheless, hydroquinone was not detected in the medium (data not shown).

We then evaluated the cell viability in the human skin model that had been topically treated with different concen-

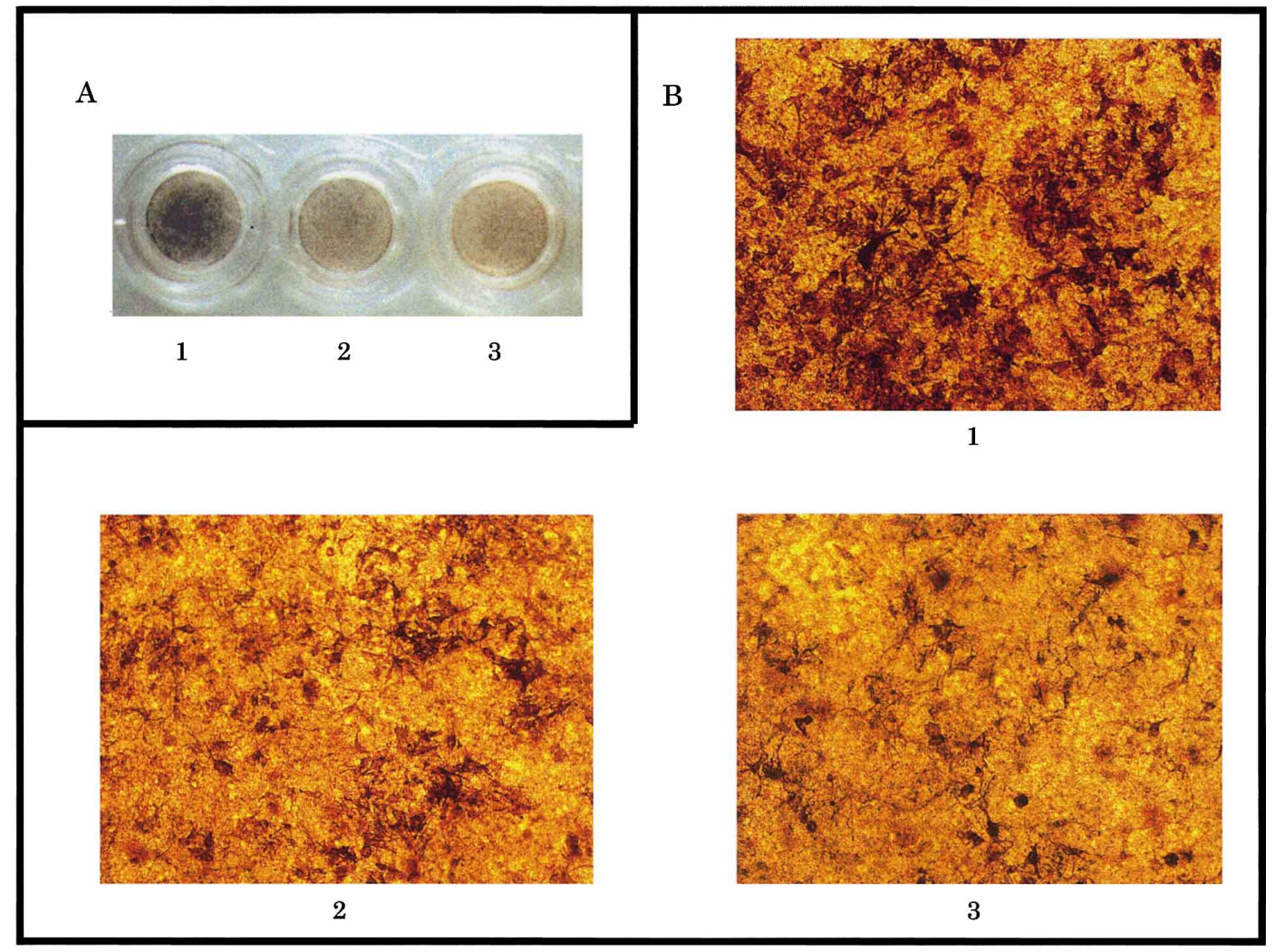

Fig. 3. Macroscopic and Microscopic Views of a Cultured Human Skin Model with and without $\alpha$-Arbutin Treatment

The human skin model was placed in 6-well plates and incubated for $13 \mathrm{~d}$. $\alpha$-Arbutin dissolved in $0.1 \mathrm{ml}$ of ultrapure water was applied to the surface of the tissues on days 0,2 , 4, 6, 8 and 10. A: Macroscopic view of the cell cultures. B: The cell cultures were observed under an inverted microscope. 1: control, 2: $125 \mu \mathrm{g} / \mathrm{tissue}, 3: 250 \mu \mathrm{g} /$ tissue. 


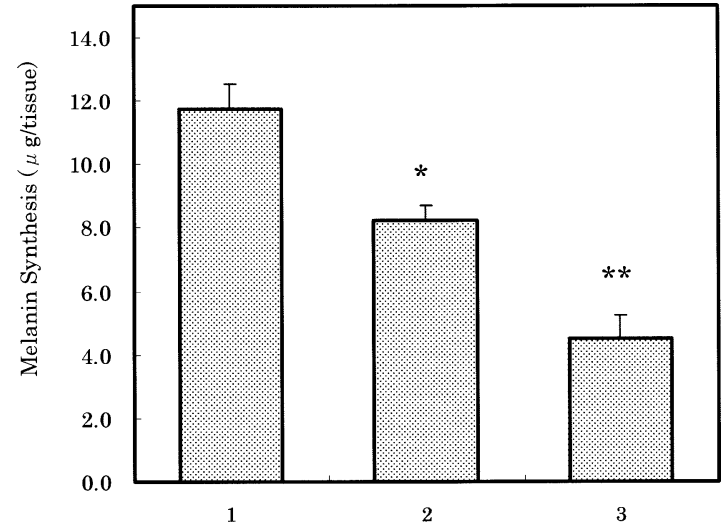

Fig. 4. Effect of $\alpha$-Arbutin on Melanin Synthesis in a Cultured Human Skin Model

The human skin model was cultured with topical doses of $\alpha$-arbutin as described in Fig. 3, and the melanin content of the tissue was assayed quantitatively. 1: control, 2 : $125 \mu \mathrm{g} /$ tissue, 3: $250 \mu \mathrm{g} /$ tissue. Bars represent means \pm S.E. of three independent experiments. * Significantly different from the non-treated control group at $p<0.05$. ** Significantly different from the non-treated control group and other $\alpha$-arbutin-treated groups at $p<0.05$



Fig. 5. Effect of $\alpha$-Arbutin on Cytotoxicity in a Cultured Human Skin Model

The human skin model was cultured with topical doses of $\alpha$-arbutin for $12 \mathrm{~d}$ and then with ultrapure water for an additional $3 \mathrm{~d}$. The viability of the human skin model was determined by MTT assay, as described in Materials and Methods. 1: control, 2 $250 \mu \mathrm{g} / \mathrm{tissue}$, 3: $500 \mu \mathrm{g} / \mathrm{tissue}$. The results are expressed as \% control, and the bars represent means \pm S.E. of three independent experiments. NS, no significant change.

trations of $\alpha$-arbutin by MTT assay. No significant decrease in cell viability was observed when the tissue was treated with up to $500 \mu \mathrm{g}$ of $\alpha$-arbutin (Fig. 5). These results suggest that topical treatment of the tissue with $\alpha$-arbutin decreased melanin synthesis without affecting cell viability.

\section{DISCUSSION}

$\alpha$-Arbutin produced a concentration-dependent inhibition of melanin synthesis of human melanoma cells, HMV-II. Cell growth was not affected by $\alpha$-arbutin at concentrations lower than $1.0 \mathrm{~mm}$. Tyrosinase activity in cells treated with $0.5 \mathrm{~mm}$ was reduced to $60 \%$ of that in non-treated cells, while the expression of tyrosinase mRNA was unaffected. The decrease in melanin synthesis in $\alpha$-arbutin-treated cells was well correlated with the inhibition of cellular tyrosinase activity by $\alpha$-arbutin. Therefore, the inhibitory effects of $\alpha$-arbutin on melanogenesis may be due to the direct inhibition of melanosomal tyrosinase activity, rather than the suppression of cell growth or tyrosinase gene expression.
Several researchers have reported that arbutin, an optical isomer of $\alpha$-arbutin, also reduced cellular tyrosinase activity in human melanocyte culture and human melanoma cells at noncytotoxic concentrations, ${ }^{11-13)}$ and that the expression level of tyrosinase mRNA was unaffected by arbutin.,11,12) Chakraborty et al. reported that there was no change in protein content or the molecular size of human tyrosinase between before and after arbutin treatment by immunoblotting experiments. They suggested that the inhibition of tyrosinase activity by arbutin might be due to its effects at the posttranslational level. ${ }^{13)}$ It is unclear whether $\alpha$-arbutin and arbutin, both of which are derivatives of hydroquinone glucosides, inhibit cellular tyrosinase activity via the same mechanism.

We also evaluated the effect of $\alpha$-arbutin on a human skin model, i.e., epidermal equivalents containing melanocytes. Its inhibitory effect on melanin synthesis was confirmed by quantitative measurements of melanin as well as macro- and microscopic observations of tissue pigmentation. Several researchers have indicated that human epidermal equivalents containing melanocytes and keratinocytes provide a convenient and reliable alternative to animal testing for evaluating the regulation of mammalian pigmentation. ${ }^{14,15)}$ Our results indicated that $\alpha$-arbutin also affects melanogenesis in this human skin model. Furthermore, this effect was observed without any detectable cytotoxicity to the human skin model. The inhibitory effects of hydroquinone on melanogenesis are considered to be due to the inhibition of tyrosinase in melanocytes and to its cytotoxicity toward melanocytes. ${ }^{16-19)}$ However, HPLC analysis showed that while $70 \%$ of $\alpha$-arbutin applied to the human skin model was recovered in the medium, hydroquinone was not detected at all after cultivation. These results suggest that the inhibitory effect of $\alpha$-arbutin on melanin synthesis was not due to the action of hydroquinone released from $\alpha$-arbutin.

In this study, it was difficult to compare the inhibitory effect of $\alpha$-arbutin on the human skin model with that on HMV-II melanoma cells. When $250 \mu \mathrm{g}$ of $\alpha$-arbutin $(100 \mu \mathrm{l}$ of $0.25 \%$ ) was applied to the tissue, the original concentration was calculated to be approximately $9 \mathrm{~mm}$, which is much higher than that applied to melanoma cells $(0.5 \mathrm{~mm})$. However, the final concentration of $\alpha$-arbutin that permeated through the tissue into the medium was estimated to be less than $0.18 \mathrm{~mm}$. This may partly explain the difference in sensitivity between the two assay systems that we used. We are now seeking to characterize the inhibitory effects of $\alpha$-arbutin and its derivatives on melanogenesis in normal human melanocytes.

In conclusion, these results suggest that $\alpha$-arbutin may be a novel candidate for a skin-lightening agent in the cosmetic industry.

\section{REFERENCES}

1) Nishimura T., Kometani T., Takii H., Terada Y., Okada S., J. Ferment. Bioeng., 78, 31-36 (1994).

2) Funayama M., Arakawa H., Yamamoto R., Nishino T., Shin T., Murao S., Biosci. Biotech. Biochem., 59, $143-144$ (1995).

3) Kitao S., Sekine H., Biosci. Biotech. Biochem., 58, 38- 42 (1994).

4) Kurosu J., Sato T., Yoshida K., Tsugane T., Shimura S., Kirimura K., Kino K., Usami S., J. Biosci. Bioeng., 93, 328-330 (2002).

5) Nishimura T., Kometani T., Okada S., Ueno N., Yamamoto T., Yakugaku Zasshi, 115, 626-632 (1995). 
6) Sugimoto K., Nishimura T., Nomura K., Sugimoto K., Kuriki T., Chem. Pharm. Bull., 51, 798-801 (2003).

7) Hasumi K., Sakamoto G., Sugano H., Kasuga T., Masubuchi K., Cancer, 42, 2675-2686 (1978).

8) Hosoi J., Abe E., Suda T., Kuroki T., Cancer Res., 45, $1474-1478$ (1985).

9) Tomita Y., Maeda K., Tagami H., Pigment Cell Res., 5, 357-361 (1992).

10) Imai H., J. Saitama Med. School, 29, 35-50 (2002).

11) Maeda K., Fukuda M., J. Pharmacol. Exp. Ther., 276, 765-769 (1996).

12) Nakajima M., Shinoda I., Fukuwatari Y., Hayasawa H., Pigment Cell Res., 11, 12-17 (1998).
13) Chakraborty A. K., Funasaka Y., Komoto M., Ichihashi M., Pigment Cell Res., 11, 206-212 (1993).

14) Yoon T. J., Lei T. C., Yamaguchi Y., Batzer J., Wolber R., Hearing V. J., Anal. Biochem., 318, 260-269 (2003).

15) Majmudar G., Jacob G., Laboy Y., Fisher L., J. Cosmet. Sci., 49, 361 367 (1998).

16) Passi S., Nazzaro-Porro M., Br. J. Dermatol., 104, 659-665 (1981).

17) Jimbou K., Obata H., Pathak M. A., Fitzpatrick T. B., J. Invest. Dermatol., 62, 436-449 (1974).

18) Penny K. B., Smith C. J., Allen J. C., J. Invest. Dermatol., 82, 308 310 (1984).

19) Smith C. J., O’Hare K. B., Allen J. C., Pigment Cell Res., 1, 386-389 (1988). 